\title{
Care Coordination for Primary Care Practice
}

\author{
Cheryl Phillips, $M D$
}

Coordinating care for individuals with complex health care needs has long been seen as an essential component of practice to manage fragmented services and high health care costs. In particular, Medicare beneficiaries with multiple comorbid conditions account for a disproportion share of total Medicare spending. ${ }^{1}$ The National Coalition on Care Coordination, formed in 2008 and funded by the John A. Hartford Foundation, defined care coordination as a "person-centered assessmentbased interdisciplinary approach to integrating health care and social support services in which a care coordinator managed amend monitors an individual's needs, goals and preferences based on a comprehensive plan." 2

Yet, despite the strong belief in the value of such coordination, several demonstrations done by the Centers for Medicare and Medicaid Services have failed to show clear benefit. ${ }^{3}$ Most of these programs deemed to be unsuccessful relied on telephone-only interventions. However, those that did reduce Medicare costs and were seen as successful had several common elements: targeting individuals who were most likely to benefit from coordinated care; comprehensively assessing patients' risk and needs; using evidence-based care planning strategies; promoting patient and family engagement in self-care; coordinating communications between patients and providers; supporting transitions from the hospital to other settings of care; providing linkages and referrals to communitybased services; and assisting in the alignment of

From the Public Policy and Health Services, LeadingAge, Washington, DC.

Funding: none.

Conflict of interest: none declared.

Corresponding author: Cheryl Phillips, MD, Public Policy and Health Services, LeadingAge, 2519 Connecticut Avenue, NW, Washington, DC 20008 (E-mail: cphillips@ LeadingAge.org).

\section{See Related Article on Page 652.}

care options with the patient's expressed preferences. $^{4}$

Successful care coordination, therefore, must go beyond a pure "medical model" of managing referrals, coordinating diagnostic studies and reviewing medications. It must include the integration of medical and social needs, and provide supportive services identified by risk assessment, which are often outside the realm of the primary care office. Joanne Lynn, in her book, Sick to Death, ${ }^{5}$ used the following typology to categorize the subpopulations and their coordination needs:

- Previously healthy people with an acute, usually time-limited condition, which may be life-threatening.

- People with stable chronic conditions that have minimal functional and social effect in their dayto-day lives.

- People with 1 or more progressive chronic conditions who are at risk for clinical and functional decline, but can typically maintain their usual social roles.

- People with serious, progressive chronic conditions, which often includes cognitive impairment, any includes the comorbid burden of functional limitations that interfere significantly with their social roles and ability to care for themselves. This would also include those with advanced illness and end-of-life care.

She argues that the closer to the top of the list, the more pure "medical" approaches to care coordination are adequate. But those near the bottom of this list require a much broader social and medical integrated approach to service integration. A particularly vulnerable group known to be high risk and high cost, yet often overlooked in primary care practices, are those individuals who are "dually eligible" for both Medicare and Medicaid and who 
use Medicaid-covered home and communitybased services. $^{6}$

Having an interdisciplinary care model, as define by several renowned leaders in care coordination (Boult and Wieland) $)^{7}$, (Bodenheimer and Berry-

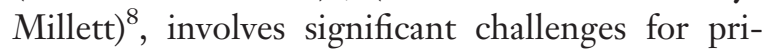
mary care practices. McCarthy, Ryan, and Klein ${ }^{9}$ identified these challenges as insufficient fee-forservice incentives to cover the program costs, difficulty with changing practice patterns and limited capacity to implement new models, lack of training and prepared workforce, often inadequate interoperability of electronic health records systems to coordinate across the care continuum, and limited evidence from single site or single condition studies to replicate across practices. ${ }^{4}$

It is clear that policy and payment changes are needed for widespread integration of care coordination into the primary care practices, particularly those smaller provider groups who are not part of large health care systems. "To improve care and reduce the financial burden on patients with complex care needs in the United States, policy makers must take a system-wide approach, strengthening primary care systems, tackling those at highest risk, increasing care and home and into the community instead of institutions, ensuring better financial protection for patients, and offering health care providers financial incentives." 10

The need for coordinating care across setting and services for individuals with complex care needs is clear. What is also clear is that 1 size does not fit all. The resources needed vary greatly between high-intensity/low-volume approaches to low-intensity/high-volume interventions. Although low-intensity approaches may include telephonebased monitoring and intermittent direct-person contact; high-intensity interventions require interdisciplinary teams, close monitoring, and frequent in-person visits. Ideally, these models are imbedded into the structure and workflow of the primary care practice infrastructure. ${ }^{11}$ Additional resources may be available to primary care practices through community-based services such as Area Agencies on Aging, Community Care Transitions programs, and service coordinators in low-income housing, but busy practices often neither know they exist or how to connect with them. Additional strategies for primary care to leverage limited resources may include the sharing of care coordination across practice sites or groups, payment that recognizes of the unique resource needs for time and travel for rural providers, and actually imbedding care management teams within the practice site.

Lastly, to truly make care coordination sustainable and to maximize the potential effect policy makers and payors need to address key issues in regulation and payment. These include the recognition that multiple models are required to meet the heterogeneity of risk and need; that successful care coordination for high-risk individuals must include the integration of social support and community-based services; that integration of funding between Medicare and Medicaid is critical to ensure access to home and community-based services that often offset higher acute care costs; that a trained workforce skilled in addressing functional and medical needs, in partnership with the patient and their family, is required; that primary care providers need additional training in team-based care; and that current fee-for-service incentives are not adequate to fund the additional staff and implementation costs associated with interdisciplinary care coordination. As stated in in in the policy brief by Moore et al, ${ }^{12}$ "Primary care practices may face difficulty dedicating an individual to provide these services," and calls on stakeholders to identify strategies for programs such as the new Merit-based Incentive Payment System and the Comprehensive Primary Care Initiative to assist small practices and those not yet transformed to a Patient Centered Medical Home to support efforts to incorporate care coordination into their daily practice.

To achieve the "triple aim" goal of improving the health of communities, improving the care experience, and reducing costs, primary care practices will need to incorporate care coordination strategies into their practice. Furthermore, as alternative payment and population health models such as accountable care organizations, managed care and bundled payments for episodes expand, primary care practices will have to use strategies to identify risk, coordinate information and patient preferences for care across settings, and integrate social and functional support services into the plan of care. Policies, payments and incentives, and training must be aligned to truly create the goal of "seamless person-centered care across time, place, and provider." 


\section{References}

1. Thorpe KE, Howard D. The rise in spending among Medicare beneficiaries; the role of chronic disease prevalence and changes in treatment intensity. Health Affairs (Millwood) 2006;25:378-388.

2. National Coalition for Care Coordination (N3C). Overview of Current Initiatives. March 2009.

3. Nelson L. Lessons from Medicare's demonstration projects on care coordination. Washington (DC): Congressional Budget Office; Jan 18, 2012.

4. Brown RS, Peikes D, Peterson G, et al. Six features of Medicare Coordinated Care Demonstrations programs that cut hospital admissions of high-risk patients. Health Affairs (Millwood) 2012;31:11561166.

5. Lynn J. Sick to death and not going to take it anymore: Reforming health care for the last years of life. Berkeley, CA: University of California, 2004.

6. Konetzka T, Karon S, Potter D. Users of Medicaid home and community-based services are especially vulnerable to costly avoidable hospital admissions. Health Affairs (Millwood) 2012;31:1167-1175.
7. Boult C, Wieland G. Comprehensive primary care for older patients with multiple chronic conditions. JAMA 2010;301:1936-1943.

8. Bodenheimer T, Berry-Millett R. Care Management of patients with complex health care needs. Research Synthesis Report No. 19. Princeton, NJ: Robert Wood Johnson Foundation, 2009.

9. McCarthy D, Ryan J, Klein S. Models of care for high-need, high-cost patients: an evidence synthesis. The Commonwealth Fund, October 29, 2015. Available from: http://www.commonwealthfund.org/ publications/issue-briefs/2015/oct/care-high-needhigh-cost-patients. Accessed October 20, 2016.

10. Martyn H, David K. Care coordination for people with complex care needs in the U.S.: A policy analysis. Int J Care Coord 2014;17(3-4):93-98.

11. Daaleman TP, Hay S, Prentice A, et al. Embedding Care Management in the Medical Home: a case study. J Prim Care Community Health 2014;5:97-100.

12. Moore M, Peterson L, Coffman M, Jabbarpour Y. Care coordination and population management services are more prevalent in large practices and patient-centered medical homes. J Am Board Fam Med 2016;29:652-3. 